\title{
RESEARCH
}

Open Access

\section{Apolipoprotein CIII predicts cardiovascular events in patients with coronary artery disease: a prospective observational study}

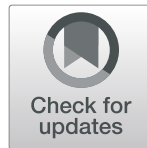

Julius L. Katzmann ${ }^{1^{*}}$ D, Christian M. Werner ${ }^{2}$, Tatjana Stojakovic ${ }^{3}$, Winfried März ${ }^{4,5,6}$, Hubert Scharnagl ${ }^{4}$ and Ulrich Laufs ${ }^{1}$

\begin{abstract}
Background: Apolipoprotein CIII (apoCIII) is associated with triglyceride-rich lipoprotein metabolism and has emerged as independent marker for risk of cardiovascular disease. The objective was to test whether apoClll is regulated postprandially and whether apoCIII concentrations in native and chylomicron-free serum predict future cardiovascular events in patients with stable coronary artery disease (CAD).
\end{abstract}

Methods: ApoCIII concentrations were measured in native and chylomicron-free serum in the fasting state and after a standardized oral fat load test in 195 patients with stable CAD. Clinical follow-up was 48 months. Chylomicron-free serum was prepared by ultracentrifugation (18,000 rpm, $3 \mathrm{~h}$ ). The log-rank test and Cox regression analyses were used to investigate the association of apoCIII with recurrent cardiovascular events.

Results: Of the 195 patients included, 92 had a cardiovascular event, and 103 did not. 97\% were treated with a statin. No significant changes in apoCIII concentration were observed after the oral fat load test. The apoCIII concentration was associated with event-free survival independent of conventional risk factors. This association reached statistical significance only for apoCIII concentration measured in chylomicron-free serum (hazard ratio [95\% confidence interval] for apoCIII above the mean: postprandial: 1.67 (1.06-2.29), $P=0.028$, fasting: 2.09 (1.32-3.32), $P=0.002$ ), but not for apoCIII concentration measured in native serum (postprandial: 1.47 [0.89-2.43], $P=0.133$, fasting: 1.56 [0.95-2.58], $P=0.081)$. The effects were independent of other risk factors.

Conclusions: ApoCIII concentrations in chylomicron-free serum are independently associated with event-free survival in patients with CAD both in fasting and postprandial state. This findings support considering apoCIII for risk assessment and attempting to test the hypothesis that lowering apoCIII reduces residual cardiovascular risk.

Take home message: Apolipoprotein CIII concentration measured in chylomicron-free serum predicts recurrent cardiovascular events in patients with stable coronary artery disease.

Trial registration: The trial which included the participants of this study was registered at https://clinicaltrials.gov (NCT00628524) on March 5, 2008.

Keywords: Apolipoprotein CIII, Chylomicron, Cardiovascular disease, Coronary artery disease, Risk factor, Antisense oligonucleotide, Triglyceride, Ultracentrifugation, Oral fat tolerance test

\footnotetext{
* Correspondence: julius.katzmann@medizin.uni-leipzig.de

${ }^{1}$ Klinik und Poliklinik für Kardiologie, Universitätsklinikum Leipzig, Liebigstraße 20, 04103 Leipzig, Germany

Full list of author information is available at the end of the article
}

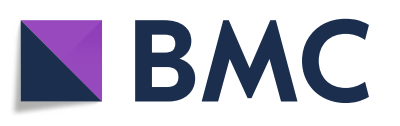

( ) The Author(s). 2020 Open Access This article is licensed under a Creative Commons Attribution 4.0 International License, which permits use, sharing, adaptation, distribution and reproduction in any medium or format, as long as you give appropriate credit to the original author(s) and the source, provide a link to the Creative Commons licence, and indicate if changes were made. The images or other third party material in this article are included in the article's Creative Commons licence, unless indicated otherwise in a credit line to the material. If material is not included in the article's Creative Commons licence and your intended use is not permitted by statutory regulation or exceeds the permitted use, you will need to obtain permission directly from the copyright holder. To view a copy of this licence, visit http://creativecommons.org/licenses/by/4.0/. The Creative Commons Public Domain Dedication waiver (http://creativecommons.org/publicdomain/zero/1.0/) applies to the data made available in this article, unless otherwise stated in a credit line to the data. 


\section{Background}

Apolipoprotein CIII (apoCIII) is produced in the liver and to a smaller extent in the intestine. It resides on apolipoprotein $\mathrm{B}$ (apoB)-containing lipoproteins (LDL, intermediate-density lipoproteins [IDL], very LDL [VLDL], chylomicrons, triglyceride-rich lipoprotein [TRL] remnants) and on HDL, between which it is exchanged rapidly [1]. ApoCIII inhibits lipoprotein lipase and hepatic VLDL uptake, and enhances hepatic VLDL secretion, by this increasing TRL levels [2-7]. Proinflammatory and prothrombotic effects of apoCIII have been described [8-10]. Furthermore, apoCIII modifies the effects of other lipoproteins: HDL particles containing apoCIII have been found to be associated with coronary artery disease (CAD) risk, while HDL particles without apoCIII were protective of CAD [11]; and the risk of CAD due to elevated LDL cholesterol appeared mainly to be due to LDL particles containing apoCIII [12], which may be mediated by the above-described mechanisms.

A causal relationship of apoCIII and cardiovascular disease (CVD) is suggested by two Mendelian randomization analyses, in which loss-of-function mutations in apoCIII resulted in $40 \%$ lower triglyceride levels and a $40 \%$ reduction in CAD risk $[13,14]$. Prospective observational studies have shown an association of apoCIII with incident CAD $[15,16]$, with this association being independent from triglyceride levels in some studies [17]. In the Ludwigshafen Risk and Cardiovascular health (LURIC) study, a J-shaped association between apoCIII and cardiovascular mortality was found [18]. Furthermore, in a meta-analysis of 12 prospective cohort and case-control studies, an association of apoCIII levels and CVD was reported [19].

Serum triglycerides are regulated postprandially. In the available studies, apoCIII was measured in the fasting or the postprandial state. Whether apoCIII concentration changes due to food intake has not yet been investigated systematically in a sufficient number of patients. Furthermore, it is not known whether the association of apoCIII with CVD reflects the exogenous or endogenous pathways of lipid metabolism, whereas the first is mainly represented by the cholesterol and triglyceride content and associated apolipoproteins of chylomicrons, and the latter by the concentration of cholesterol, triglycerides, and apolipoproteins in chylomicron-free serum [20]. This knowledge might improve risk assessment with apoCIII concentration in patients with established CVD in order to identify those at the highest residual risk most likely to benefit from rigorous risk factor control.

This study aimed to investigate the course of the apoCIII concentration after a standardized oral fat load test and to assess whether apoCIII predicts disease progression in CAD patients, comparing native and chylomicron-free serum.

\section{Methods}

This study encompasses the 195 patients from the prospective Homburg Cream and Sugar study [21] included lastly. For the main study, institutional review was provided by the ethics committee of the Saarland (Number 170/07) and all participants provided written informed consent. In brief, between February 2008 und July 2009, consecutive patients with angiographically documented clinically stable CAD were enrolled. In all patients, a standardized oral triglyceride tolerance test (OTTT) with $75 \mathrm{~g}$ fat $(250 \mathrm{~mL}$ cream drink) was performed. In patients without medical treatment for diabetes mellitus, an oral glucose tolerance test (OGTT) was performed to test for the absence of diabetes mellitus. Blood samples were collected before and 3,4 , and $5 \mathrm{~h}$ after the OTTT. Patients were followed for 48 months. After 12, 24, and 48 months, standardized telephone interviews were conducted to assess for the occurrence of primary end point events. Hospital records were consulted if patients had been hospitalized. The study end points were adjudicated by a blinded end point committee consisting of at least two experienced cardiologists blinded to the results of metabolic testing [21]. The primary end point was the composite of cardiovascular death, hospitalization for acute coronary syndrome or for unplanned, symptominduced coronary angiography, and any revascularisation including bypass surgery.

\section{Laboratory analyses}

Routine laboratory analyses were carried out in the core facility of the Universitätsklinikum des Saarlandes, Germany [21]. Lipoprotein separation and analysis was performed from frozen serum samples (stored at $-80^{\circ} \mathrm{C}$ ) at the Clinical Institute of Medical and Chemical Laboratory Diagnostics, Medical University of Graz, Austria.

Lipoproteins (chylomicrons, VLDL, LDL, and HDL) were separated using ultracentrifugation and precipitation methods. First, the chylomicron fraction was separated by ultracentrifugation $(18,000 \mathrm{rpm}, 3 \mathrm{~h})$. Lipids and apolipoproteins were measured in total serum and in the infranate after ultracentrifugation (chylomicron-free serum). Second, the chylomicron-free serum was separated in VLDL, LDL, and HDL using a combined ultracentrifugation-precipitation method (beta-quantification) $[22,23]$. In brief, VLDL were separated by ultracentrifugation $(30,000 \mathrm{rpm}, 18 \mathrm{~h})$ at a density of 1.0063 $\mathrm{kg} / \mathrm{L}$. After ultracentrifugation, the supernate (containing VLDL) was removed and lipids and apoB were measured in the infranate (containing LDL and HDL). Lipids and apoB in VLDL were calculated as difference between chylomicron-free serum and the LDL/HDL fraction. Then, LDL were precipitated with a phosphotungstic acid $/ \mathrm{MgCl}_{2}$ reagent in the infranate after removal of chylomicrons and VLDL. Lipids were measured in HDL 
and lipids in LDL were calculated as difference between HDL and the LDL/HDL fraction.

Total cholesterol (TC), free cholesterol (FC), triacylglycerides (TG), and phospholipids (PL) were measured using enzymatic reagents from Diasys (Holzheim, Germany) and were calibrated using secondary standards from Roche Diagnostics (Mannheim, Germany; TC, TG) and DiaSys (Holzheim, Germany; FC, PL). Esterified cholesterol (CE) was calculated as the difference between TC and FC. Non-esterified fatty acids (NEFA) were analysed using an enzymatic reagent (ACS-ACOD method) from Wako Chemicals (Neuss, Germany). Apolipoproteins and lipoprotein(a) were determined by immunoturbidimetry using reagents from DiaSys (Holzheim, Germany) and standards from Siemens (Marburg, Germany; apoAI, apoB, apoE), Kamiya Biomedical (Seattle, WA, USA; apoAII, apoCII, apoCIII), and DiaSys (lipoprotein[a]). All measurements were performed on an Olympus AU680 automatic analyzer. The coefficients of variation (between day) were $<5 \%$ (Supplemental Figure).

\section{Statistical analyses}

Categorical values are expressed as percent. Continuous data are expressed as mean (standard deviation). For comparison of normally distributed data (according to Kolmogorov-Smirnov test), the two-sided $t$-test was used; otherwise, the Wilcoxon test was applied. Baseline characteristics were compared with ANOVA and chi-squared test. Correlation was assessed with the Pearson correlation coefficient. The log-rank test was used to examine differences in event-free survival stratified by tertiles of apoCIII concentration. Multivariable Cox regression analyses for apoCIII concentration above vs. below the mean were performed. Tests of the proportional hazards assumption showed that out of all variables, only age had a relevant interaction. For the other covariates, model fit was not improved by using time-dependent interaction terms. Therefore, the models were adjusted for age as a timedependent variable (interaction term time*age), gender, LDL cholesterol, HOMA index, fasting triglycerides for fasting samples and 5-h triglyceride area under the curve for postprandial samples, respectively, metabolic syndrome, and smoking status.

The analyses were conducted with SPSS software version 20.0. A two-sided $P$ value $<0.05$ was considered statistically significant.

\section{Results}

The mean age of the 195 patients was 66.9 years, $87.2 \%$ of the patients were men. 92 patients (47.2\%) had a cardiovascular event during 48 months of follow-up, and 103 did not. Of the 92 cardiovascular events, the majority were symptom-induced coronary angiography $(n=$ 81). $N=5$ patients had non-fatal myocardial infarction, and $n=6$ patients died of cardiovascular causes. In consequence, $n=42$ patients received unplanned percutaneous coronary intervention (PCI) and $\mathrm{n}=6$ patients were surgically treated with aortocoronary bypass operation.

The medication was similar in both groups, $97.4 \%$ were treated with a statin. More patients without event during follow-up were actively smoking ( $23.3 \%$ vs. $10.9 \%$ of the patients with event; $P=0.017)$. Alcohol consumption in this group was slightly higher $(22.3 \%$ drinking alcohol more than three times a week vs. $19.6 \%$ ). $67 \%$ of the patients without event had diabetes mellitus compared to $75 \%$ of patients with event. The differences in alcohol consumption and diabetes did not reach statistical significance. Fasting triglycerides were higher in patients with event (168.4 [117.7] vs. 135.6 [67.6] $\mathrm{mg} / \mathrm{dL}$; $P=0.016$ ), total, LDL, and HDL cholesterol were comparable. The baseline characteristics are shown in Table 1.

The changes in apolipoproteins after the OTTT in native and chylomicron-free serum are depicted in Table 2 . Apolipoprotein concentrations were characterized in four states: in fasting state in native (1) and chylomicron-free (2) serum and in postprandial state in native (3) and chylomicron-free (4) serum. After $5 \mathrm{~h}$, mean apoCIII levels showed a non-significant minor increase when measured in native serum and a slight decrease when measured in chylomicron-free serum, corresponding to an absolute increase of $0.2 \mathrm{mg} / \mathrm{dL}$ $(3.7 \%)$ in native serum and a $0.2 \mathrm{mg} / \mathrm{dL}$ decrease $(0.6 \%)$ in chylomicron-free serum $(P=0.122$ for native serum, $P=0.288$ in chylomicron-free serum). Apolipoproteins AI, AII, B and E did not change relevantly after OTTT in native and chylomicron-free serum.

The fasting and postprandial apoCIII concentrations (as measured in chylomicron-free serum) were significantly associated with body mass index, fasting glucose, diabetes mellitus, and metabolic syndrome. An inverse association was observed with age. In regard to other lipoproteins, there were strong correlations of the apoCIII concentration with triglycerides and total cholesterol. LDL and HDL cholesterol did not show significant correlations with apoCIII (Tables 3 and 4).

The apoCIII concentration was higher in patients with a cardiovascular event during follow-up. This association did not reach statistical significance for the apoCIII concentration measured in native serum $(P=0.122$ fasting, $P=0.095$ postprandial). In contrast, the apoCIII concentration measured in chylomicron-free serum was significantly associated with the primary end point. This association was stronger in the postprandial state $(P=$ 0.035 fasting, $P=0.008$ postprandial). The data are shown in Table 5 .

In Fig. 1, the Kaplan-Meier curves for event-free survival stratified by apoCIII tertiles as measured in 
Table 1 Baseline characteristics

\begin{tabular}{|c|c|c|c|c|}
\hline & All & No event & Event & $\boldsymbol{P}$ value \\
\hline \multicolumn{5}{|l|}{ General } \\
\hline$N=$ & 195 & 103 & 92 & - \\
\hline Age in years & $66.9(10.2)$ & $66.3(11.0)$ & $67.7(9.2)$ & 0.358 \\
\hline Male & $87.2(170)$ & $88.3(91)$ & $85.9(79)$ & 0.380 \\
\hline Received OGTT & $56.4(110)$ & $60.2(62)$ & $52.2(48)$ & 0.163 \\
\hline \multicolumn{5}{|l|}{ Medical History } \\
\hline Previous myocardial infarction & $43.1(84)$ & 37.9 (39) & $48.9(45)$ & 0.079 \\
\hline Cardiac bypass surgery & $13.8(27)$ & $9.7(10)$ & $18.5(17)$ & 0.059 \\
\hline Previous stroke or TIA & $9.2(18)$ & $9.7(10)$ & $8.7(8)$ & 0.503 \\
\hline Peripheral artery disease & $7.7(15)$ & $10.7(11)$ & $4.3(4)$ & 0.081 \\
\hline \multicolumn{5}{|l|}{ Medication } \\
\hline Platelet inhibitors & $96.9(189)$ & $96.1(99)$ & $97.8(90)$ & 0.396 \\
\hline ACE inhibitors/ARBs & $96.4(188)$ & $95.1(98)$ & $97.8(90)$ & 0.271 \\
\hline Beta blockers & $91.8(179)$ & $88.3(91)$ & $95.7(88)$ & 0.054 \\
\hline Statins & $97.4(190)$ & $98.1(101)$ & 96.7 (89) & 0.447 \\
\hline \multicolumn{5}{|l|}{ Clinical characteristics } \\
\hline Smoking (active) & $17.4(34)$ & $23.3(24)$ & $10.9(10)$ & 0.017 \\
\hline Alcohol regularly & $21.0(41)$ & $22.3(23)$ & $19.6(18)$ & 0.384 \\
\hline Positive family history & $34.3(67)$ & $35.9(37)$ & $32.6(30)$ & 0.369 \\
\hline Hypertension & $95.9(187)$ & $92.2(95)$ & $100.0(92)$ & 0.005 \\
\hline Systolic blood pressure in $\mathrm{mmHg}$ & $126.1(15.1)$ & $124.4(13.8)$ & $128.0(16.4)$ & 0.095 \\
\hline Diastolic blood pressure in $\mathrm{mmHg}$ & $74.6(8.1)$ & $74.0(8.1)$ & $75.3(8.1)$ & 0.246 \\
\hline Resting heart rate in $\mathrm{min}^{-1}$ & $66.6(8.4)$ & $66.8(8.2)$ & $66.4(8.8)$ & 0.771 \\
\hline LV ejection fraction in \% & $62.3(12.3)$ & $62.7(11.9)$ & $61.9(12.8)$ & 0.664 \\
\hline Body mass index in $\mathrm{kg} / \mathrm{m}^{2}$ & $28.8(3.9)$ & $28.4(4.1)$ & $29.2(3.6)$ & 0.194 \\
\hline Waist circumference in $\mathrm{cm}$ & $103.8(10.5)$ & $103.0(10.5)$ & $104.8(10.4)$ & 0.224 \\
\hline Waist-to-hip ratio & $1.00(0.06)$ & $1.00(0.06)$ & $1.01(0.07)$ & 0.477 \\
\hline \multicolumn{5}{|l|}{ Metabolic characterization } \\
\hline Normal glucose tolerance & $29.2(57)$ & $33.0(34)$ & $25.0(23)$ & 0.142 \\
\hline Impaired glucose tolerance & $24.1(47)$ & $24.3(25)$ & $23.9(22)$ & \\
\hline Diabetes mellitus & $46.7(91)$ & $42.7(44)$ & $51.1(47)$ & \\
\hline Metabolic syndrome & $59.5(116)$ & $51.5(53)$ & $68.5(63)$ & 0.011 \\
\hline Fasting glucose in mg/dL & $129.9(38.2)$ & $128.4(37.4)$ & $131.7(39.2)$ & 0.557 \\
\hline Fasting insulin in $\mu \mathrm{lU} / \mathrm{mL}$ & $10.7(9.7)$ & $9.9(7.8)$ & $11.5(11.4)$ & 0.238 \\
\hline HOMA index & $3.42(4.08)$ & $3.04(3.29)$ & $3.83(4,81)$ & 0.177 \\
\hline $\mathrm{HbA} 1 \mathrm{c}$ in $\%$ & $6.0(1.1)$ & $5.9(0.8)$ & $6.2(1.3)$ & 0.063 \\
\hline Total cholesterol in mg/dL & $174.9(38.4)$ & $173.3(36.3)$ & $176.6(40.8)$ & 0.550 \\
\hline $\mathrm{HDL}$ cholesterol in mg/dL & $44.9(13.5)$ & $44.9(11.3)$ & $45.0(15.7)$ & 0.970 \\
\hline LDL cholesterol in mg/dL & $106.4(34.1)$ & $107.0(33.3)$ & $105.7(35.2)$ & 0.802 \\
\hline Non-HDL cholesterol mg/dL & $129.9(138.2)$ & $128.4(37.4)$ & $131.7(39.2)$ & 0.557 \\
\hline Fasting triglycerides in $\mathrm{mg} / \mathrm{dL}$ & $151.1(95.7)$ & $135.6(67.5)$ & $168.4(117.7)$ & 0.016 \\
\hline Postprandial 5 h-Tg-AUC in mg/dL & 1065 (599) & $979(477)$ & $1161(701)$ & 0.033 \\
\hline C-reactive protein in mg/dL & $4.8(8.7)$ & $4.6(7.3)$ & $5.0(10.1)$ & 0.741 \\
\hline
\end{tabular}

Numerical variables are presented as mean (standard deviation), the other variables are $\%(\mathrm{n})$, or as otherwise indicated. OGTT oral glucose tolerance test, TIA transient ischemic attack, ACE angiotensin-converting enzyme, ARB angiotensin II receptor blocker, $L V$ left ventricular, HOMA homeostasis model assessment, $T g$ triglycerides, $A U C$ area under the curve 
Table 2 Apolipoproteins after oral fat tolerance test in native and in chylomicron-free serum

\begin{tabular}{|c|c|c|c|c|c|c|}
\hline & ApoAl & ApoAll & ApoB & ApoCll & ApoCIII & ApoE \\
\hline \multicolumn{7}{|l|}{ Native Serum } \\
\hline $\mathrm{Oh}$ & $134.2(26.4)$ & $37.0(8.5)$ & $82.6(24.9)$ & $3.1(1.4)$ & $10.0(3.7)$ & $11.5(3.2)$ \\
\hline $5 \mathrm{~h}$ & $132.3(25.1)$ & $36.9(8.7)$ & $81.1(25.2)$ & $3.2(1.5)$ & $10.2(3.9)$ & $11.8(3.4)$ \\
\hline Absolute change (mg/dL) & $-1.9(15.0)$ & $-0.2(3.6)$ & $-1.4(8.4)$ & $0.0(0.6)$ & $0.2(1.5)$ & $0.4(1.4)$ \\
\hline Proportional change (\%) & $-0.6(13.5)$ & $-0.1(10.6)$ & $-1.4(9.7)$ & $1.8(24.0)$ & $3.7(23.1)$ & $3.6(12.6)$ \\
\hline$P$ value & 0.076 & $0.402^{\mathrm{a}}$ & 0.019 & $0.953^{\mathrm{a}}$ & $0.122^{\mathrm{a}}$ & $0.001^{\mathrm{a}}$ \\
\hline \multicolumn{7}{|l|}{ Chylomicron-free serum } \\
\hline $\mathrm{Oh}$ & $122.1(26.8)$ & $32.3(8.5)$ & $57.3(20.7)$ & $2.4(1.2)$ & $7.5(4.1)$ & $9.6(2.9)$ \\
\hline $5 \mathrm{~h}$ & $121.4(26.9)$ & $32.0(8.3)$ & $55.1(20.1)$ & $2.2(1.1)$ & $7.3(4.2)$ & $9.4(2.8)$ \\
\hline Absolute change (mg/dL) & $-0.7(19.7)$ & $-0.4(5.0)$ & $-2.3(9.2)$ & $-0.2(0.6)$ & $-0.2(1.9)$ & $-0.2(1.6)$ \\
\hline Proportional change (\%) & $-0.5(15.9)$ & $-0.2(18.0)$ & $-1.8(26.3)$ & $-0.6(31.4)$ & $-0.6(37.4)$ & $-0.0(17.8)$ \\
\hline$P$ value & 0.622 & 0.268 & 0.001 & $<0.001^{\mathrm{a}}$ & 0.288 & 0.190 \\
\hline
\end{tabular}

Values are in $\mathrm{mg} / \mathrm{dL}$ and presented as mean (standard deviation) if not stated otherwise. $h$ hours. ${ }^{a}$ Wilcoxon test, otherwise $t$ test

chylomicron-free serum are depicted in fasting (Fig. 1a) and postprandial state (Fig. 1b). The apoCIII concentration in chylomicron-free serum both in the fasting and the postprandial state was significantly associated with a higher probability of events. This association was stronger in postprandial than in fasting state (hazard ratio [HR] [95\% CI] for third vs. first tertile: postprandial: 2.12 [1.26-3.56], $P=0.004$, fasting: 1.74 [1.05-2.90], $P=$ 0.031 ). If the same analyses were conducted with apoCIII concentration measured in native serum, statistical significance was not reached (postprandial: $P=0.060$, fasting: $P=0.105)$. In contrast to apoCIII concentration, no other apolipoprotein or other lipid parameters were associated with the primary end point in native or chylomicron-free serum (apoAI, AII, B, CII, E, free fatty acids, lipoprotein[a], free cholesterol, cholesteryl esters, phospholipids; supplemental Table).

In multivariable Cox regression analyses, apoCIII concentration above compared to below the mean in chylomicron-free serum was associated with the primary end point when adjusted for age"time and gender (HR [95\% CI] postprandial: 1.79 [1.18-2.71], $P=0.006$, fasting: 2.17 [1.42-3.31], $P<0.001)$. Additionally adjusting for LDL cholesterol, HOMA index, fasting triglycerides for fasting samples and 5-h triglyceride area under the curve for postprandial samples, respectively, metabolic syndrome, and smoking status, apoCIII was associated with the primary end point with a HR $(95 \% \mathrm{CI})$ of 1.67 $(1.06-2.29)$ postprandial $(P=0.028)$ and $2.09(1.32-3.32)$ fasting $(P=0.002)$. In contrast, when measured in native serum, apoCIII concentration above vs. below the mean was not significantly associated with the primary end point (HR [95\% CI] postprandial: 1.47 [0.89-2.43], $P=$ 0.133 , fasting: 1.56 [0.95-2.58], $P=0.081$ ). The results for apoCIII measurement in chylomicron-free serum are shown in Fig. 2. The apoCIII concentration in chylomicron-free serum was also associated with the primary end point when apoCIII was used as continuous variable. Per $\mathrm{mg} / \mathrm{dL}$ increase in apoCIII, in the minimally adjusted model, the HR (95\% CI) was 1.06 (1.01-1.11), $P=0.019$ fasting and $1.02(1.02-1.11), P=0.007$ postprandial, and in the extensively adjusted model, 1.05 (0.98-1.12), $P=0.152$ fasting and 1.07 (1.00-1.13), $P=$ 0.036 postprandial.

\section{Discussion}

This study has two main findings: First, apoCIII concentrations did not change significantly after standardized oral fat intake; and second, a strong association of apoCIII concentration was found in chylomicron-free serum, but not native serum, in the fasting and postprandial state with recurrent cardiovascular events in CAD patients, even after adjustment for conventional risk factors. This findings imply that in CAD patients, apoCIII concentration in chylomicron-free serum may be a superior predictor of disease progression than apoCIII concentration in native serum. Patients with high apoCIII may benefit from rigorous risk factor control.

Changes of the apoCIII concentration after fat intake could have been expected, as previous smaller studies in healthy subjects have shown slight decreases of apoCIII concentration after a duodenal fat infusion $(n=10)$ [24], after oral fat intake $(n=16)$ [25], and after several weeks of diet rich in monounsaturated fatty acids $(n=47)$ [26]. In another investigation of 58 in-patients, no relevant changes in apoCIII concentration during the course of a single day were observed [27]. Similarly, a recent study did not find changes in total apoCIII concentration in $n=91$ inpatients after a meal [28]. In contrast, in a casecontrol subgroup of the Leipzig LIFE-Heart study $(n=$ 911), apoCIII concentration was 7.3\% higher postprandially compared to fasting state [29]. Using a highly 
Table 3 Correlation of apoCIII concentration in chylomicronfree serum fasting and postprandial with baseline characteristics and other lipid parameters

\begin{tabular}{|c|c|c|c|c|}
\hline & \multicolumn{2}{|c|}{ Fasting } & \multicolumn{2}{|c|}{ Postprandial } \\
\hline & $R$ & $\boldsymbol{P}$ value & $R$ & $\boldsymbol{P}$ value \\
\hline \multicolumn{5}{|l|}{ Clinical characteristics } \\
\hline Age & -0.18 & 0.012 & -0.15 & 0.041 \\
\hline Body mass index & 0.20 & 0.005 & 0.21 & 0.004 \\
\hline \multicolumn{5}{|c|}{ Clinical chemistry parameters in native serum } \\
\hline Fasting glucose & 0.39 & $<0.001$ & 0.32 & $<0.001$ \\
\hline HOMA index & 0.05 & 0.520 & 0.07 & 0.369 \\
\hline $\mathrm{HbA1c}$ & 0.12 & 0.098 & 0.14 & 0.064 \\
\hline C-reactive protein & -0.11 & 0.151 & -0.08 & 0.287 \\
\hline Total cholesterol & 0.36 & $<0.001$ & 0.294 & $<0.001$ \\
\hline LDL cholesterol & 0.14 & 0.061 & 0.08 & 0.301 \\
\hline HDL cholesterol & -0.08 & 0.263 & -0.07 & 0.378 \\
\hline Non-HDL cholesterol & 0.39 & $<0.001$ & 0.32 & $<0.001$ \\
\hline Remnant cholesterol & 0.68 & $<0.001$ & 0.63 & $<0.001$ \\
\hline Fasting triglycerides & 0.68 & $<0.001$ & 0.63 & $<0.001$ \\
\hline \multicolumn{5}{|c|}{ Lipid parameters in lipoprotein subfractions } \\
\hline Total cholesterol in CFS & -0.09 & 0.223 & 0.01 & 0.933 \\
\hline Triglycerides in CFS & 0.24 & 0.001 & 0.31 & $<0.001$ \\
\hline Chylomicron cholesterol & 0.46 & $<0.001$ & 0.36 & $<0.001$ \\
\hline Chylomicron triglycerides & 0.67 & $<0.001$ & 0.53 & $<0.001$ \\
\hline VLDL cholesterol & -0.08 & 0.275 & 0.16 & 0.024 \\
\hline VLDL triglycerides & 0.18 & 0.012 & 0.29 & $<0.001$ \\
\hline LDL cholesterol & -0.13 & 0.076 & -0.08 & 0.278 \\
\hline LDL triglycerides & 0.08 & 0.303 & 0.05 & 0.469 \\
\hline HDL cholesterol & 0.20 & 0.006 & 0.21 & 0.003 \\
\hline $\mathrm{HDL}$ triglycerides & 0.30 & $<0.001$ & 0.28 & $<0.001$ \\
\hline
\end{tabular}

$R$ : Pearson correlation coefficient, HOMA homeostasis model assessment, CFS: chylomicron-free serum

Table 4 ApoCIII concentration in chylomicron-free serum fasting and postprandial stratified by metabolic syndrome and diabetes-related traits

\begin{tabular}{llllllll}
\hline $\begin{array}{l}\text { ApoCIII concentrations in } \\
\text { metabolic syndrome and } \\
\text { diabetes }\end{array}$ & & Fasting & & & \multicolumn{2}{l}{ Postprandial } \\
Metabolic syndrome & yes & $8.2(4.7)$ & 0.003 & & $7.9(4.8)$ & 0.026 \\
& no & $6.4(2.7)$ & & & $6.5(3.0)$ & \\
IFG, IGT, Diabetes & yes & $8.0(4.4)$ & 0.013 & & $7.7(4.5)$ & 0.038 \\
& no & $6.3(3.1)$ & & & $6.3(3.2)$ & \\
\hline
\end{tabular}

Values for apoClll are in $\mathrm{mg} / \mathrm{dL}$ and presented as mean (standard deviation). IFG impaired fasting glucose, IGT impaired glucose tolerance standardized metabolic test protocol, no significant changes in apoCIII concentration were observed postprandially, neither in native nor in chylomicron-free serum. A strength of this study compared to the abovementioned studies is the standardized metabolic test protocol and the high level of metabolic and cardiovascular characterization of the participants.

Despite known effects of glucose as activator of apoCIII expression and of insulin as inhibitor [30, 31], these were not reflected in changes in apoCIII concentration in the patients who had an OGTT $(n=110$, apoCIII [SD] in native serum: fasting 9.8 [3.6] $\mathrm{mg} / \mathrm{dL}$, after test 10.0 [3.6] mg/dL, $P=0.071$, chylomicron-free serum: fasting $7.4[4.5] \mathrm{mg} / \mathrm{dL}$, after test $7.4[4.7] \mathrm{mg} / \mathrm{dL}, P=$ 0.972). One could speculate that the effects of glucose and insulin counteracted. Alternatively, the standard OGTT test protocol may be too short to detect glucoseinduced changes via transcriptional activation or the changes could have been too small to be captured in this study. However, the observed association of diabetes mellitus and apoCIII concentration suggests an interplay between glucose metabolism and apoCIII.

ApoCIII concentrations were associated with cardiovascular events upon follow-up. This association reached statistical significance when apoCIII was measured in chylomicron-free serum, but not in native serum. This indicates differences between the chylomicron-bound proportion of apoCIII and the proportion of apoCIII not attached to chylomicrons. The chylomicron-bound proportion of apoCIII seems to mask the prognostic effect of the proportion of apoCIII bound by lipoproteins other than chylomicrons. After removing chylomicrons, this encompasses especially IDL, VLDL, and HDL [32]. This finding could be explained either by interpreting apoCIII as marker for the associated lipoproteins: chylomicrons cannot penetrate the arterial intima because of their size and are not associated with cardiovascular risk, whereas IDL and VLDL are associated with cardiovascular risk [33, 34]; or by interpreting apoCIII as being atherogenic by itself, whereas its atherogenic properties differ according to the lipoproteins it is bound to. It is likely that the interchange of the apoCIII proportion not bound to chylomicrons between different lipoproteins may also play a role and modulate the associated risk without changing total apoCIII concentration. This observation sets the stage for future studies on apoCIII associated with different lipoproteins [1]. Irrespective of this, and also taking into account that apoCIII was not significantly regulated postprandially, the association of apoCIII and CAD is more likely to be due to the endogenous rather than the exogenous pathways of lipid metabolism.

A similar relationship between apoCIII concentration and cardiovascular risk in CAD patients has been reported previously in two studies. Olivieri et al. reported 
Table 5 Primary end point for native and chylomicron-free serum fasting and after fat tolerance test

\begin{tabular}{|c|c|c|c|c|c|}
\hline & & Primary end point & $\mathrm{n}=$ & ApoCIII in mg/dL (SD) & $\boldsymbol{P}$ value \\
\hline \multirow[t]{4}{*}{ Native serum } & fasting & No & 103 & $9.6(3.5)$ & 0.122 \\
\hline & & Yes & 92 & $10.4(3.8)$ & \\
\hline & postprandial & No & 103 & $9.8(3.9)$ & 0.095 \\
\hline & & Yes & 92 & $10.7(3.9)$ & \\
\hline \multirow[t]{4}{*}{ Chylomicron-free serum } & fasting & No & 101 & $6.9(3.9)$ & 0.035 \\
\hline & & Yes & 87 & $8.2(4.3)$ & \\
\hline & postprandial & No & 102 & $6.6(3.7)$ & 0.008 \\
\hline & & Yes & 87 & $8.2(4.6)$ & \\
\hline
\end{tabular}

fasting apoCIII as independent predictor of cardiovascular mortality [35]. A nested case-control analysis from the CARE trial showed that fasting apoCIII concentrations of VLDL and LDL were independent predictors of recurrent cardiovascular events [36]. The HRs for cardiovascular events in the subgroups with high apoCIII in both studies were 2 to 2.5, i.e. remarkably similar to the findings observed in this study. The present study shows that beyond the independent role of triglycerides in predicting cardiovascular events [21], assessment of apoCIII provides additional information to stratify this high-risk population. This may help to identify patients with the highest risk who will, in absolute terms, benefit most from an intervention that reduces residual cardiovascular risk.

Taken together, the current evidence suggests a causal role of apoCIII in CVD. However, it is not clear whether lowering of apoCIII will reduce CVD risk and if apoCIII by itself or the retarded clearance of remnant lipoproteins due to higher apoCIII concentration are causal drivers of CVD [37]. The recent REDUCE-IT study reported that high-dose icosapent ethyl reduces CVD risk in patients with elevated triglycerides [38]. Antisense oligonucleotides that inhibit apoCIII synthesis proved successful in decreasing apoCIII, triglyceride concentrations and other VLDL-associated apolipoproteins [15, 39-41]. These and other emerging therapeutic strategies may allow to test the importance of apoCIII for cardiovascular risk in the future.

\section{Limitations}

A potential limitation of this study is the sample size. Furthermore, statin therapy, which was established in the majority of the patients, may have influenced the observed associations. However, as most CAD patients are treated with statins, this reflects the typical situation in cardiovascular prevention, and underpins that also under statin therapy, apoCIII may be a promising therapeutic
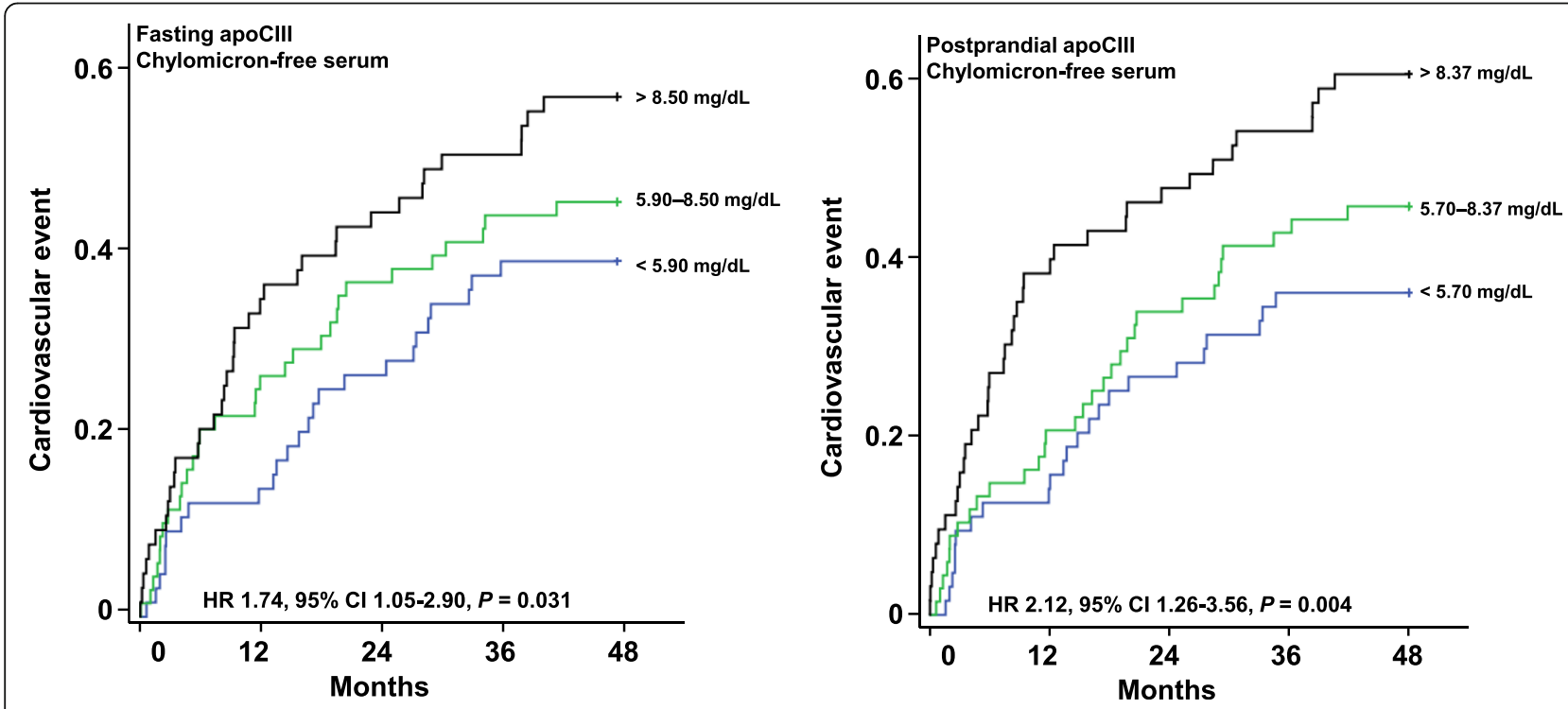

Fig. 1 Kaplan-Meier curves of event-free survival for 48 months, stratified by tertiles of apoCIII concentrations in chylomicron-free serum fasting (a) and postprandial after standardized fat load test (b). HR: hazard ratio, Cl: confidence interval 


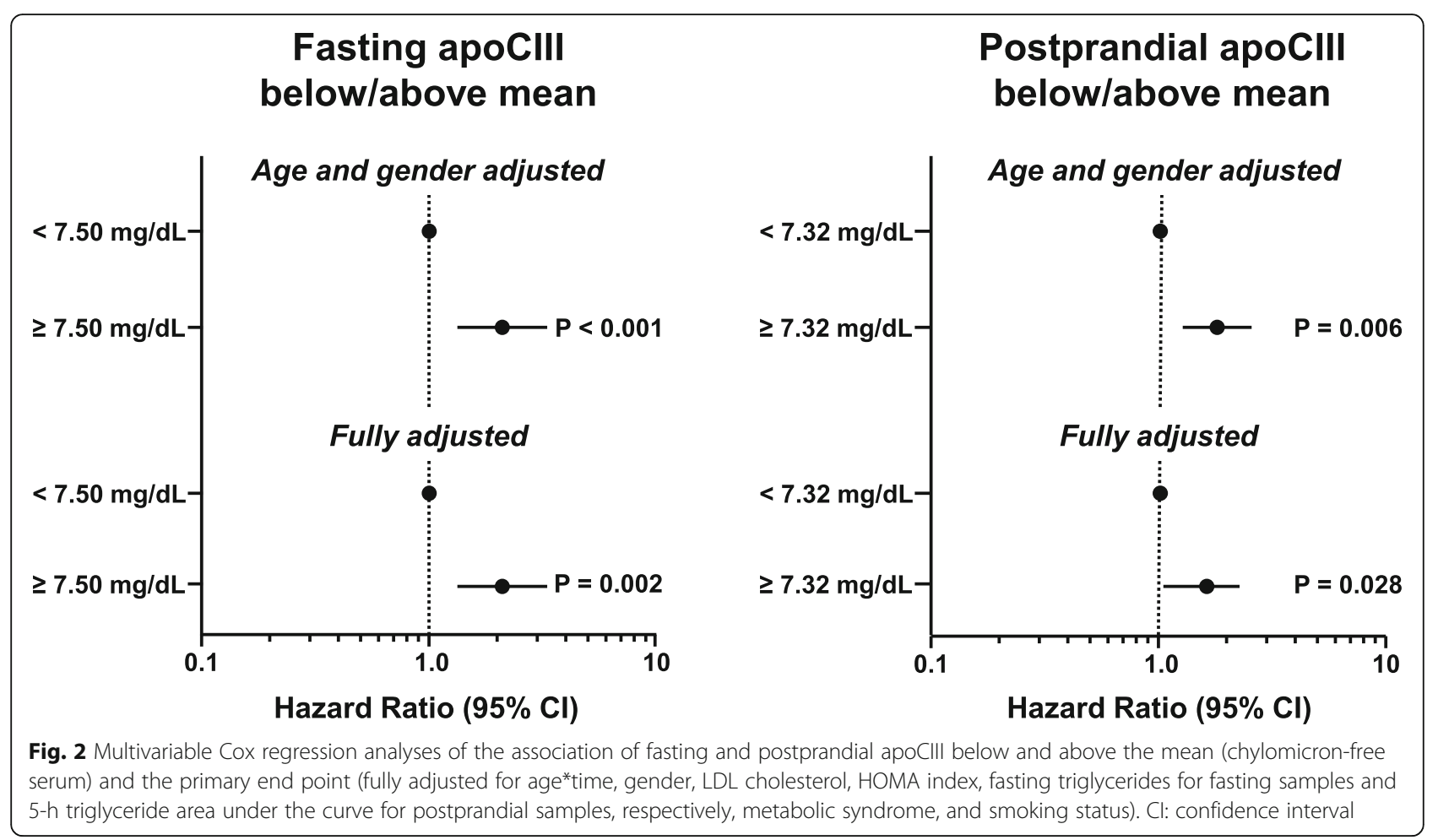

target. Strengths include the rigorous metabolic test protocol, the long follow-up, and the prospective design.

\section{Conclusions}

In conclusion, no significant changes in apoCIII concentration after standardized fat load were observed. ApoCIII concentration measured in chylomicron-free, but not native serum, predicted future cardiovascular events in patients with CAD. ApoCIII concentration may be a superior risk marker to predict residual cardiovascular risk when measured in chylomicron-free serum, independently of food intake, however this finding needs to be confirmed in larger studies. Patients with elevated apoCIII may benefit from more rigorous risk factor control. The findings of this study support testing the effects of specific lowering of apoCIII, e.g. with antisense oligonucleotides targeting apoCIII mRNA, on residual cardiovascular risk.

\section{Supplementary information}

Supplementary information accompanies this paper at https://doi.org/1 0.1186/s12944-020-01293-9

Additional file 1: Figure S1. Workflow of detailed lipid characterization. * Chylomicron fraction: calculated as difference between total serum and chylomicron-free serum. \# LDL fraction: calculated as difference between LDL/HDL fraction (infranate after removal of VLDL) and HDL fraction. Apo: apolipoprotein, TG: triglycerides, PL: phospholipids, FFA: free fatty acids.

Additional file 2: Table S1. Kaplan-Meier analyses for apolipoproteins and other lipid parameters.
Abbreviations

apo: apolipoprotein; IDL: Intermediate-density lipoprotein; TRL: Triglyceriderich lipoprotein; CVD: Cardiovascular disease; CAD: Coronary artery disease; OTT: Oral triglyceride tolerance test; OGTT: Oral glucose tolerance test; TC: Total cholesterol; FC: Free cholesterol; TG: Triacylglycerides;

PL: Phospholipids; EC: Esterified cholesterol; NEFA: Non-esterified fatty acids

\section{Acknowledgements}

Not applicable.

\section{Authors' contributions}

J.K., U.L., and C.W. designed the study, and analysed and interpreted the data, C.W. conducted the study, J.K. and U.L. wrote the article, T.S., W.M., and H.S. conducted the laboratory analyses. All authors critically revised the manuscript and approved the final article.

\section{Funding}

This research did not receive any specific grant from funding agencies in the public, commercial, or not-for-profit sectors.

\section{Availability of data and materials}

The datasets generated and/or analysed during the current study are not publicly available because consent to publish individual participant data was not obtained from the participants of this study. The datasets are available from the corresponding author on reasonable request.

Ethics approval and consent to participate Institutional review was provided by the ethics committee of the Saarland (Number 170/07) and all participants provided written informed consent.

\section{Consent for publication}

Not applicable.

Competing interests

The authors declare that they have no competing interests. 


\section{Author details}

${ }^{1}$ Klinik und Poliklinik für Kardiologie, Universitätsklinikum Leipzig, Liebigstraße 20, 04103 Leipzig, Germany. ${ }^{2}$ Klinik für Innere Medizin III, Kardiologie, Angiologie und Internistische Intensivmedizin, Universitätsklinikum des Saarlandes, Homburg, Germany. ${ }^{3}$ Klinisches Institut für Medizinische und Chemische Labordiagnostik, LKH Universitätsklinikum Graz, Graz, Austria. ${ }^{4}$ Klinisches Institut für Medizinische und Chemische Labordiagnostik, Medizinische Universität Graz, Graz, Austria. ${ }^{5}$ Medizinische Klinik V, Medizinische Fakultät Mannheim, Universität Heidelberg, Mannheim, Germany. ${ }^{6}$ Synlab Academy, Synlab Holding Deutschland GmbH, P5, 7, Mannheim, Germany.

Received: 15 October 2019 Accepted: 20 May 2020 Published online: 30 May 2020

\section{References}

1. Ooi EMM, Barrett PHR, Chan DC, Watts GF. Apolipoprotein C-III: understanding an emerging cardiovascular risk factor. Clin Sci. 2008;114: 611-24. https://doi.org/10.1042/CS20070308

2. Ginsberg HN, Le NA, Goldberg IJ, Gibson JC, Rubinstein A, Wang-Iverson P, et al. Apolipoprotein B metabolism in subjects with deficiency of apolipoproteins CIII and Al. Evidence that apolipoprotein CIII inhibits catabolism of triglyceride-rich lipoproteins by lipoprotein lipase in vivo. J Clin Invest. 1986:78:1287-95. https://doi.org/10.1172/JCl112713.

3. McConathy WJ, Gesquiere JC, Bass H, Tartar A, Fruchart JC, Wang CS. Inhibition of lipoprotein lipase activity by synthetic peptides of apolipoprotein C-III. J Lipid Res. 1992;33:995-1003.

4. Windler $E$, Havel RJ. Inhibitory effects of $C$ apolipoproteins from rats and humans on the uptake of triglyceride-rich lipoproteins and their remnants by the perfused rat liver. J Lipid Res. 1985;26:556-65.

5. Zheng C, Khoo C, Furtado J, Sacks FM. Apolipoprotein C-III and the metabolic basis for hypertriglyceridemia and the dense low-density lipoprotein phenotype. Circulation. 2010;121:1722-34. https://doi.org/10. 1161/CIRCULATIONAHA.109.875807

6. Sundaram M, Zhong S, Bou Khalil M, Links PH, Zhao Y, lqbal J, et al. Expression of apolipoprotein C-III in McA-RH7777 cells enhances VLDL assembly and secretion under lipid-rich conditions. J Lipid Res. 2010;51:15061. https://doi.org/10.1194/M900346-JLR200

7. Yao Z. Human apolipoprotein C-III - a new intrahepatic protein factor promoting assembly and secretion of very low density lipoproteins. Cardiovasc Hematol Disord Drug Targets. 2012;12:133-40.

8. Kawakami A, Aikawa M, Alcaide P, Luscinskas FW, Libby P, Sacks FM. Apolipoprotein CIII induces expression of vascular cell adhesion molecule-1 in vascular endothelial cells and increases adhesion of monocytic cells. Circulation. 2006;114:681-7. https://doi.org/10.1161/CIRCULATIONAHA.106. 622514

9. Zheng C, Azcutia V, Aikawa E, Figueiredo J-L, Croce K, Sonoki H, et al. Statins suppress apolipoprotein CIII-induced vascular endothelial cell activation and monocyte adhesion. Eur Heart J. 2013;34:615-24. https://doi.org/10.1093/ eurheartj/ehs271.

10. Martinelli N, Baroni M, Castagna A, Lunghi B, Stefanoni F, Tosi F, et al. Apolipoprotein C-III strongly correlates with activated factor VII-antithrombin complex: an additional link between plasma lipids and coagulation. Thromb Haemost. 2019. https://doi.org/10.1055/s-0038-1676817

11. Jensen MK, Rimm EB, Furtado JD, Sacks FM. Apolipoprotein C-III as a potential modulator of the association between $\mathrm{HDL}$-cholesterol and incident coronary heart disease. J Am Heart Assoc. 2012. https://doi.org/10. 1161/JAHA.111.000232.

12. Mendivil CO, Rimm EB, Furtado J, Chiuve SE, Sacks FM. Low-density lipoproteins containing apolipoprotein C-III and the risk of coronary heart disease. Circulation. 2011;124:2065-72. https://doi.org/10.1161/ CIRCULATIONAHA.111.056986.

13. Crosby J, Peloso GM, Auer PL, Crosslin DR, Stitziel NO, Lange LA, et al. Lossof-function mutations in APOC3, triglycerides, and coronary disease. N Engl J Med. 2014;371:22-31. https://doi.org/10.1056/NEJMoa1307095

14. Jørgensen AB, Frikke-Schmidt R, Nordestgaard BG, Tybjærg-Hansen A. Lossof-function mutations in APOC3 and risk of ischemic vascular disease. $\mathrm{N}$ Engl J Med. 2014;371:32-41. https://doi.org/10.1056/NEJMoa1308027 .

15. Pechlaner $R$, Tsimikas $S$, Yin X, Willeit $P$, Baig F, Santer $P$, et al. Very-lowdensity lipoprotein-associated Apolipoproteins predict cardiovascular events and are lowered by inhibition of APOC-III. J Am Coll Cardiol. 2017;69:789800. https://doi.org/10.1016/j.jacc.2016.11.065

16. van Capelleveen JC, Bernelot Moens SJ, Yang X, Kastelein JJP, Wareham NJ, Zwinderman $\mathrm{AH}$, et al. Apolipoprotein C-III levels and incident coronary artery disease risk: the EPIC-Norfolk prospective population study. Arterioscler Thromb Vasc Biol. 2017;37:1206-12. https://doi.org/10.1161/ ATVBAHA.117.309007

17. Scheffer PG, Teerlink T, Dekker JM, Bos G, Nijpels G, Diamant M, et al. Increased plasma apolipoprotein C-III concentration independently predicts cardiovascular mortality: the Hoorn study. Clin Chem. 2008;54:1325-30. https://doi.org/10.1373/clinchem.2008.103234

18. Silbernagel G, Scharnagl H, Kleber ME, Grammer TB, Delgado G, Stojakovic T, et al. J-shaped association of circulating apolipoprotein C3 with cardiovascular mortality. Atherosclerosis. 2017;263:e89-90. https://doi.org/10. 1016/j.atherosclerosis.2017.06.292 .

19. Wyler von Ballmoos MC, Haring B, Sacks FM. The risk of cardiovascular events with increased apolipoprotein CIII: A systematic review and meta-analysis. J Clin Lipidol. 2015;9:498-510. https://doi.org/10.1016/j.jacl.2015.05.002 .

20. Kwiterovich PO. The metabolic pathways of high-density lipoprotein, lowdensity lipoprotein, and triglycerides: a current review. Am J Cardiol. 2000; 86:5L-10L.

21. Werner C, Filmer A, Fritsch M, Groenewold S, Gräber S, Böhm M, Laufs U. Risk prediction with triglycerides in patients with stable coronary disease on statin treatment. Clin Res Cardiol. 2014;103:984-97. https://doi.org/10.1007/ s00392-014-0740-0

22. Bachorik PS, Ross JW. National Cholesterol Education Program recommendations for measurement of low-density lipoprotein cholesterol: executive summary. The National Cholesterol Education Program Working Group on lipoprotein measurement. Clin Chem. 1995;41:1414-20.

23. Wanner $\mathrm{C}$, Hörl WH, Luley $\mathrm{CH}$, Wieland $\mathrm{H}$. Effects of HMG-CoA reductase inhibitors in hypercholesterolemic patients on hemodialysis. Kidney Int. 1991:39:754-60.

24. Barr SI, Kottke BA, Mao SJ. Postprandial distribution of apolipoproteins C-II and C-III in normal subjects and patients with mild hypertriglyceridemia: comparison of meals containing corn oil and medium-chain triglyceride oil. Metabolism. 1985;34:983-92.

25. Annuzzi G, Holmquist L, Carlson LA. Concentrations of apolipoproteins B, CI, C-II, C-III, E and lipids in serum and serum lipoproteins of normal subjects during alimentary lipaemia. Scand J Clin Lab Invest. 1989;49:73-81.

26. Archer WR, Desroches S, Lamarche B, Deriaz O, Landry N, Fontaine-Bisson B, et al. Variations in plasma apolipoprotein C-III levels are strong correlates of the triglyceride response to a high-monounsaturated fatty acid diet and a high-carbohydrate diet. Metabolism. 2005;54:1390-7. https://doi.org/10. 1016/j.metabol.2005.05.004 .

27. Kosuge K, Miida T, Takahashi A, Obayashi K, Ito M, Ito T, et al. Estimating the fasting triglyceride concentration from the postprandial HDL-cholesterol and apolipoprotein CIII concentrations. Atherosclerosis. 2006:184:413-9. https://doi.org/10.1016/j.atherosclerosis.2005.05.037

28. Zhang T, Tang X, Mao L, Chen J, Kuang J, Guo X, et al. HDL-associated apoCIII plays an independent role in predicting postprandial hypertriglyceridemia. Clin Biochem. 2020;79:14-22. https://doi.org/10.1016/j. clinbiochem.2020.02.004

29. Dittrich J, Beutner F, Teren A, Thiery J, Burkhardt R, Scholz M, Ceglarek U. Plasma levels of apolipoproteins C-III, A-IV, and E are independently associated with stable atherosclerotic cardiovascular disease. Atherosclerosis. 2018;281:17-24. https://doi.org/10.1016/j.atherosclerosis.2018.11.006

30. Caron S, Verrijken A, Mertens I, Samanez CH, Mautino G, Haas JT, et al. Transcriptional activation of apolipoprotein CIII expression by glucose may contribute to diabetic dyslipidemia. Arterioscler Thromb Vasc Biol. 2011;31: 513-9. https://doi.org/10.1161/ATVBAHA.110.220723.

31. Li WW, Dammerman MM, Smith JD, Metzger S, Breslow JL, Leff T. Common genetic variation in the promoter of the human apo CIII gene abolishes regulation by insulin and may contribute to hypertriglyceridemia. J Clin Invest. 1995;96:2601-5. https://doi.org/10.1172/JCl118324

32. Wulff AB, Nordestgaard BG, Tybjærg-Hansen A. APOC3 loss-of-function mutations, remnant cholesterol, low-density lipoprotein cholesterol, and cardiovascular risk: mediation- and meta-analyses of 137895 individuals. Arterioscler Thromb Vasc Biol. 2018;38:660-8. https://doi.org/10.1161/ ATVBAHA.117.310473

33. Varbo A, Benn M, Tybjærg-Hansen A, Jørgensen AB, Frikke-Schmidt $R$, Nordestgaard BG. Remnant cholesterol as a causal risk factor for ischemic 
heart disease. J Am Coll Cardiol. 2013;61:427-36. https://doi.org/10.1016/j. jacc.2012.08.1026

34. Nordestgaard BG, Tybjaerg-Hansen A. IDL, VLDL, chylomicrons and atherosclerosis. Eur J Epidemiol. 1992;8(Suppl 1):92-8.

35. Olivieri O, Martinelli N, Girelli D, Pizzolo F, Friso S, Beltrame F, et al. Apolipoprotein C-III predicts cardiovascular mortality in severe coronary artery disease and is associated with an enhanced plasma thrombin generation. J Thromb Haemost. 2010;8:463-71. https://doi.org/10.1111/j. 1538-7836.2009.03720.x

36. Sacks FM, Alaupovic P, Moye LA, Cole TG, Sussex B, Stampfer MJ, et al. VLDL, Apolipoproteins $\mathrm{B}, \mathrm{CIII}$, and $\mathrm{E}$, and risk of recurrent coronary events in the cholesterol and recurrent events (CARE) trial. Circulation. 2000;102:1886-92. https://doi.org/10.1161/01.CIR.102.16.1886

37. Cohen JC, Stender S, Hobbs HH. APOC3, coronary disease, and complexities of Mendelian randomization. Cell Metab. 2014;20:387-9. https://doi.org/10. 1016/j.cmet.2014.08.007

38. Bhatt DL, Steg PG, Miller M, Brinton EA, Jacobson TA, Ketchum SB, et al. Cardiovascular risk reduction with Icosapent ethyl for hypertriglyceridemia. N Engl J Med. 2019;380:11-22. https://doi.org/10.1056/NEJMoa1812792 .

39. Gaudet D, Alexander VJ, Baker BF, Brisson D, Tremblay K, Singleton W, et al. Antisense inhibition of Apolipoprotein C-III in patients with hypertriglyceridemia. N Engl J Med. 2015;373:438-47. https://doi.org/10. 1056/NEJMoa1400283

40. Gaudet D, Brisson D, Tremblay K, Alexander VJ, Singleton W, Hughes SG, et al. Targeting APOC3 in the familial chylomicronemia syndrome. N Engl J Med. 2014:371:2200-6. https://doi.org/10.1056/NEJMoa1400284

41. Graham MJ, Lee RG, Bell TA, Fu W, Mullick AE, Alexander VJ, et al. Antisense oligonucleotide inhibition of apolipoprotein C-III reduces plasma triglycerides in rodents, nonhuman primates, and humans. Circ Res. 2013; 112:1479-90. https://doi.org/10.1161/CIRCRESAHA.111.300367.

\section{Publisher's Note}

Springer Nature remains neutral with regard to jurisdictional claims in published maps and institutional affiliations.

Ready to submit your research? Choose BMC and benefit from:

- fast, convenient online submission

- thorough peer review by experienced researchers in your field

- rapid publication on acceptance

- support for research data, including large and complex data types

- gold Open Access which fosters wider collaboration and increased citations

- maximum visibility for your research: over $100 \mathrm{M}$ website views per year

At $\mathrm{BMC}$, research is always in progress.

Learn more biomedcentral.com/submissions 